\title{
On the process of recognizing inverted words: Does it rely only on orientation-invariant cues?
}

\author{
DAVID NAVON and OFRA RAVEH \\ University of Haifa, Haifa, Israel
}

\begin{abstract}
Following a demonstration by Parks (1983) of failure to notice the reflection of a letter of an inverted word, two experiments were conducted to test a hypothesis about the process of recognizing inverted words that is termed here invariant cues only (ICO) - a letter-by-letter identification process based only on orientation-invariant letter features. In Experiment 1, subjects were presented with whole strings-words and nonwords, either upright or inverted-in which either all the letters were normal or one of the letters was reflected, and they were asked to make lexical decisions. In Experiment 2, subjects made a reflection judgment about an upright or inverted letter within a string immediately after they had been presented with the other, nonreflected string letters, again either upright or inverted. The results do not support the ICO hypothesis: Lexical decisions were greatly affected by the reflection of a letter in upright and inverted stimuli alike. Reflection judgments were considerably facilitated by word context in the upright and the inverted modes alike. The results are accommodated better by the notion that recognition of disoriented words requires some correction used to restore orientationsensitive features.
\end{abstract}

Reading upside-down texts is certainly not a well practiced skill for most fluent readers. ${ }^{1}$ Nevertheless, people can do it. Most people ${ }^{2}$ read upside-down words much better than they read words transformed in any other way (e.g., reflection or inversion of individual letters; Kolers, 1968), although the cost is substantial in that case as well (also see, e.g., Cohen \& Squire, 1980; Driver \& Baylis, 1995; Kolers \& Perkins, 1969a, 1969b, 1975; Koriat \& Norman, 1984, 1985; Masson, 1986; Navon, 1978). Furthermore, in some conditions words seem to be identified somewhat faster when presented in the $180^{\circ}$ orientation than in $240^{\circ}$ or $120^{\circ}$ orientations (see, e.g., Jordan \& Huntsman, 1990; Koriat \& Norman, 1985). It is not clear whether these effects are due to practice or to some inherent advantage in processing. In any event, they suggest that reading inverted texts is not just cognitive acrobatics but, rather, a task that is mastered reasonably well, though clearly not nearly as well as normal reading. The issue addressed here is how it is done. More specifically, how are inverted words recognized?

\section{What the Process Might Be}

An extreme possibility is that the process governing the reading of inverted texts is completely independent of

This study was conducted as a follow-up to a study conducted by the second author as her M.A. thesis under the supervision of the first author and David Budescu. We thank David Budesco for his useful advice, Kevin Jordan, Michael Masson, and Jay Rueckl for their helpful comments, Hagit Tal and Dalia Mevorach for programming the experiments, Yaron Maoz for running them, and Ronen Kasten for conducting data analyses. Correspondence concerning this article should be addressed to D. Navon, Department of Psychology, University of Haifa, Haifa 31905, Israel (e-mail: dnavon@psy.haifa.ac.il). the process of reading upright texts, possibly executed by a dedicated module. For example, it is conceivable that in the course of practicing reading of inverted texts, readers develop special schemata and learn to use disorientationspecific templates or features. This is not totally implausible a priori. After all, readers know how to map different patterns onto the same grapheme-uppercase and lowercase, block and script, for example. However, several arguments suggest that this possibility is not quite viable. First, the identification of single letters or letterlike stimuli might be affected little by planar orientation (Corballis \& Nagourney, 1978; Corballis, Zbrodoff, Shetzer \& Butler, 1978; Eley, 1982; Koriat \& Norman, 1989; White, 1980; but see Jolicœur \& Landau, 1984; Jordan \& Huntsman, 1995; McMullen \& Jolicœur, 1990). Were that indeed the case, it would be wasteful if the product of single letter identification was not used in the process of reading inverted texts. Second, it is widely believed, mainly on the basis of the monotonicity of performance in angular deviation from the upright, that disoriented stimuli are processed with reference to their canonic representations (Cooper, 1975; Cooper \& Shepard, 1973; Corballis, 1982; Gibson \& Peterson, 1994; Jolicœur \& Humphrey, 1998; Rock, 1973; Shepard \& Cooper, 1982; Shepard \& Metzler, 1971). This certainly has some functional advantage. Finally, some regularity, though not strict monotonicity, has been found also in the function relating latency of word recognition to angular deviation from the upright (see, e.g., Koriat \& Norman, 1984, 1985; but see Jordan \& Huntsman, 1995, for some deviation from monotonicity). That suggests that there is just one process of identification resorting to just one set of cues, and that it is somehow affected by disorientation. 
But how is the process affected? Koriat and Norman (1989) found that disorientation effects were especially marked for words that could be confused with other words having the same letters in a different order. They concluded that letter order information is disrupted by disorientation, so that some operation has to restore it. That, however, cannot be the only source of the disorientation deficit. If it were, it would have been easier to recognize a word whose letters were locally inverted than a completely inverted word, since letter order is intact in the former. Yet reading of texts inverted in the former fashion is significantly slower than reading when the whole text is inverted (Kolers, 1968; Kolers \& Perkins, 1969a, 1969b; Navon, 1978). In any case, the finding that there is a problem of information regarding letter order leads one to wonder what it is that causes that problem in disoriented words, considering that the order itself is actually intact given the overall deviation in orientation.

The source of the problem may be the fact that disorientation renders it difficult, if not totally impractical, to make use of orientation-sensitive recognition cues (namely, direction and within-letter horizontal location of letter features, direction and horizontal location of supraletter features, and horizontal location of letters). It is theoretically possible that those cues are neglected, as quite a few authors have posited occurs in letter identification (e.g., Cooper \& Shepard, 1973; Corballis, 1982; Corballis et al., 1978), resulting in an orientation-free recognition process using only orientation-invariant cues (see, e.g., Marr \& Nishihara, 1978). Alternatively, the process possibly employs some compensatory normalization operation that helps restore the input word to a form admitted by an orientation-dependent recognition process (see, e.g., Jolicœur \& Milliken, 1989; Tarr \& Pinker, 1989). Let us refer to these possibilities as invariant cues only (ICO) and rectification, respectively.

Some kind of rectification is prevalently posited or presupposed in the literature dealing with perceptual processing of disoriented verbal stimuli, as is illustrated by the not infrequent cases of matter-of-course usage of the term mental rotation (see, e.g., Cohen \& Squire, 1980; Koriat \& Norman, 1984, 1985, 1989). Plausible as it may seem, this postulate could stand some experimental testing. If not for the a priori sense of the alternative, such testing is called for by a demonstration that seems incompatible with the notion of rectification. Parks (1983) reported that observers read an inverted verbal stimulus having one reflected letter (specifically, "richard gregory" with the "a" inverted) without noticing the anomaly. Since the reflection distorts some orientation-sensitive cues (specifically, the direction of some letter features and the spatial relationship between the reflected letter and at least one adjacent letter) to an extent that would be quite noticeable in upright stimuli, glossing over it in inverted stimuli suggests that such cues are not readily accessible in the course of processing inverted stimuli. It is true that demonstration is anecdotal and relies on introspection. Furthermore, the fact that distortion or dele- tion of a certain cue may sometimes go unnoticed does not prove that the cue is gratuitous. For example, the prevalence of proofreaders' errors certainly does not indicate that orthography is immaterial for word recognition. Nonetheless, even if the burden of proof has not quite been shifted, a further, more systematic test seems in order. But first, let us try to specify the alternatives better.

\section{Neglect Versus Rectification}

The ICO hypothesis posits that only orientationinvariant cues are used for identifying inverted words, whereas orientation-sensitive cues are neglected. ${ }^{3}$ That loss of identification-relevant information naturally leads to some deficit in performance.

The considerable effect of letter order confusions suggests a special kind of process, comprised of a first stage of letter-by-letter identification in which the outputs are sequentially incremented in some store, followed by a second stage in which word recognition is applied to the contents of that store. Order confusions might be due to some interference that is effected within that store or on retrieval from it. Such a process, being dependent only on orientation-invariant letter features, must be totally insensitive to any other recognition cues and, hence, resemble a process of perceiving nonwords. In the following, we use the label neglect to refer to that sort of process.

The rectification hypothesis, on the other hand, assumes that when inverted words are identified some correction is applied either to the input or to the process itself, akin to preprocessing procedures employed in mechanical pattern recognition (see, e.g., Suen, 1986, for a review). That enables the utilization of all recognition cues, but at the cost of longer latencies due to the operation of correction.

The term rectification is actually an umbrella for various alternative correction operations. Rectification may be analog or digital. It may be based on planar rotation or on some other compensating operations (such as the concatenation of horizontal reflection and vertical reflection; see Kolers \& Perkins, 1975, p. 235). Such operations may be continuous or quantal. Correction may be global or piecemeal (see Navon, 1978). It may precede identification or be intertwined with it, or required perhaps just for the sake of verification (Corballis, 1988; but see Gibson \& Peterson, 1994). Finally, it may be applied to the input or to the recognition test itself. One prominent possibility is that rectification is accomplished by a slow, continuous process akin to what is prevalently called mental rotation (Cooper, 1975; Cooper \& Podgorny, 1976; Cooper \& Shepard, 1973; Corballis, 1982; Shepard \& Cooper, 1982; Shepard \& Metzler, 1971). This was proposed by Koriat and Norman (1984, 1985, 1988). Yet, there are other possibilities. For example, rectification may be mediated by some computational modification of a representation or a procedure (such as multiplying each coordinate in a Cartesian vector representation by -1 ; see Navon, 1978). In the following, we 
do not try to test between specific versions of rectification, but only to find out whether or not there is sufficient evidence to rule out the alternative - namely, the ICO hypothesis.

\section{The Logic of the Test}

In the experiments reported here, words and nonwords were presented in $0^{\circ}$ and $180^{\circ}$ orientations with one or none of their letters reflected about the vertical axis. String length and position of the reflected letter were varied, mainly to attain generality and generate some uncertainty across trials.

In Experiment 1, we basically examined the effect of reflection on a task that called for word recognition, specifically lexical decision. In order to test the ICO hypothesis, we used the following rationale: If orientationsensitive features were neglected, reflection of a letter of an inverted word would typically go unnoticed and hence would probably have no effect, or at most a minute one, on performance of lexical decision with inverted strings.

On the other hand, the rectification hypothesis, in whichever variant one might conceive of, does not predict any considerable interaction between orientation and reflection, since rectification preserves or restores all orientation-sensitive features.

Other interactions with orientation, or the absence thereof, might suggest something about the nature of rectification. A global correction operation applied to the preprocessed string, such as global mental rotation, would predict no interaction of orientation with any other factor, with the possible exception of string length, which must affect the rate of rectification proper. If orientation were found to interact with other factors, that would suggest a more complex rectification process.

\section{EXPERIMENT 1}

In this experiment, subjects were asked to make lexical decisions on visually presented strings. We manipulated the planar orientation of the stimulus string and studied the effect of reflecting one of its letters.

As was noted above, some orientation-sensitive cues that may be used in word recognition are distorted by reflection. If inverted words were recognized only by orientation-invariant letter features, as posited by the ICO hypothesis, then reflection would affect neither the accuracy nor the speed of responding to inverted words. The risk is that even if the deviation of the word from its usual form were detected, it would be too small to have a discernible effect on the response. If this is the case, that insensitivity would be revealed in upright words. Nevertheless, if reflection did affect responses to upright words but not to inverted ones, that would support the ICO hypothesis. A considerable reflection effect in inverted words, on the other hand, would be hard to reconcile with it, and hence would suggest by default that disoriented words were somehow being rectified. A quite similar prediction can be made for nonwords. Since letter identifi- cation is somewhat sensitive to reflection (Corballis et al., 1978) and nonwords are probably coded letter by letter even when presented upright, reflection may affect coding of upright nonwords as well. If inverted nonwords were coded only by orientation-invariant letter features, as is posited by the ICO hypothesis, reflection would not affect their coding. Thus, the ICO hypothesis predicts that orientation and reflection would have a strong interactive effect on lexical decision.

String length was systematically manipulated. Recognition of words is known to be practically insensitive to number of letters, in contrast with the processing of nonwords (see, e.g., Frederiksen \& Kroll, 1976; Koriat \& Norman, 1985). It has been shown that recognition of inverted words is rather affected by word length (Koriat \& Norman, 1985; Navon, 1978). That seems to be consistent with the ICO hypothesis, but it may also be reconciled with the rectification hypothesis, since the rectification process proper may be sensitive to string length (e.g., mental rotation is often found to depend on stimulus complexity_-Hochberg \& Gellman, 1977; Pringle \& Cowan, 1978; Pylyshyn, 1979; Yuille \& Steiger, 1982).

The same is true for another factor that was systematically manipulated - namely, the position of the reflected letter. A main effect of position could be due to differential impacts on encoding of various serial positions, to differential salience of orientation-sensitive features in various positions, or to differential availability of configural information in various positions. It does not seem that there is an easy way to ascertain which of these factors was operative. Since the ICO hypothesis posits that a reflection of any letter of an inverted string would go unnoticed, it of course predicts no effect of position of the reflected letter for inverted stimuli. On the other hand, such a result would hardly be embarrassing for the notion of rectification in its broad sense, since it is easy to conceive of a variant of it that allows some differences between processing of rectified previously inverted strings and processing of upright ones.

\section{Method}

Subjects. Thirty-two subjects participated. All were native Hebrew speakers and had normal or corrected-to-normal vision. All were paid for their participation.

Apparatus and setting. Each subject was run through the experiment individually. The experiment was controlled by a MicroVax-II Workstation computer. The stimuli were presented on the graphical display of the computer. The subject sat in front of the screen. Eye distance was $80 \mathrm{~cm}$ from the screen.

Stimuli. Five hundred twelve different strings were used. The strings differed on lexicality - that is, they were either words or nonwords. The 256 words were either Hebrew words or Hebrew transliterations of frequent foreign words. All the words had one reading when unvowelized. ${ }^{4}$ The nonwords were anagrams of the words. Strings could be four, five, six, or seven letters long. The position of the letter to be reflected under the reflection condition was manipulated. The four values of this variable depended on string length in the following manner: The first value was always the first position, the fourth value was always the last position, whereas the second and third values corresponded to intermediate positions to the right and left of the word center, respectively (He- 

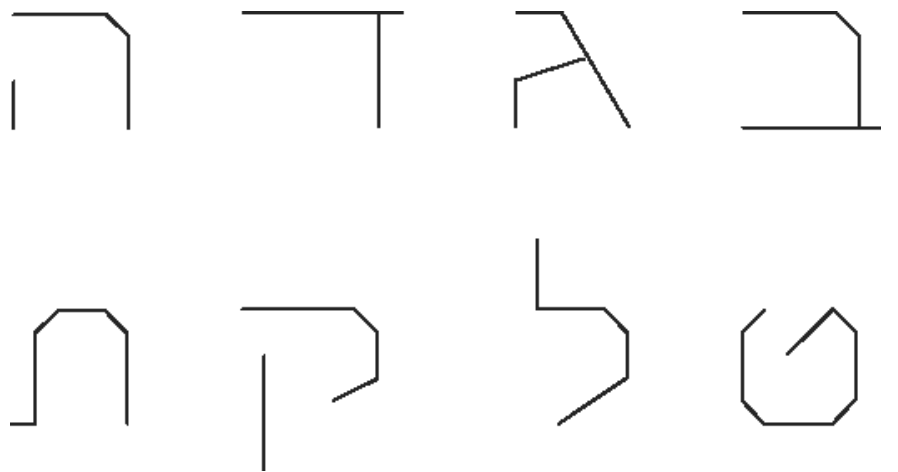

Figure 1. The eight Hebrew letters that could be reflected. Their names, from right to left, are bet, gimel, dalet, hey, tet, lamed, quf, and tav.

brew is read from right to left). Accordingly, the positions were 1, 2,3 , and 4 in four-letter strings; $1,2,4$, and 5 in five-letter strings; 1,2 or 3,4 or 5 , and 6 in six-letter strings; and 1,2 or 3,5 or 6 , and 7 in seven-letter strings. The identity of the reflected letter could be any of the eight presented in Figure 1. The four string variables were factorially crossed with two replications per cell (with the single exception that since only one seven-letter word ending with the letter bet was found, the second replication in that cell was substituted by a word ending with the letter hey).

Strings were presented at the center of the screen surrounded by a rectangular frame. The letters measured $6 \mathrm{~mm}\left(.43^{\circ}\right.$ of visual angle) vertically and about $4 \mathrm{~mm}\left(.29^{\circ}\right.$ of visual angle $)$ horizontally, not counting extensions. The distance between two adjacent letters ranged from 1 to $3 \mathrm{~mm}$. The frame measured $15 \mathrm{~mm}$ vertically and $40 \mathrm{~mm}$ horizontally.

Procedure and Design. Each subject was run through the experiment individually in one session. In every trial, a string was presented and the subject had to indicate whether it was a word or a nonword by pressing one of two keys. Trials varied on two factors: orientation and reflection. In other words, the string could be presented upright or inverted and a reflection could be present or absent (see panel A of Figure 2 for an example of an upright word with no reflected letter, and panel B for an example of an inverted word with one letter reflected). The onset of the string was 250 msec later than the onset of the frame. Both the string and the frame remained on until the subject responded or until $10 \mathrm{sec}$ had elapsed without a response. Intertrial interval was $500 \mathrm{msec}$.

There were 512 experimental trials in blocks of 128 trials each. Each subject was presented once with each of the 512 strings. Orientation and reflection were factorially crossed within subjects, and order of presentation was random. The frequency of strings with a reflected letter was twice as high as the frequency of normal strings. Presentation conditions were paired with stimuli in the following manner: The stimuli were divided into eight equal subsets. Each subset consisted of all combinations of the four positions with the four string lengths, of all the letter identities, but not of all the triple combinations. Stimulus subsets were then paired with the combinations of presentation conditions (orientation $\times$ reflection $\times$ cue delay) according to an $8 \times 8$ Latin square, in such a way that each subject was presented with one row of the square and across subjects all possible pairings were used. To any subject, different rows were assigned for words and for nonwords.

Thirty-two practice trials were given at the beginning of the session. All factors were represented in those trials with about the same proportions as in the experimental trials. Finger-response mapping was counterbalanced across subjects.

\section{Results and Discussion}

Analyses of variance (ANOVAs) were performed on cell medians of latencies of correct responses and on arcsine square root transforms of cell proportions of errors.

All data from all of the subjects were submitted to a four-way analysis (orientation $\times$ reflection $\times$ string length $\times$ lexicality). Another analysis was used to test the factor of position and its interactions, so it was performed only on trials with a reflected letter and included the model orientation $\times$ position $\times$ string length $\times$ lexicality. Further analyses were performed within levels of some factors that were found to interact with others.

Median latencies and error percentages for all values of all factors are presented in Table 1. $F$ and $p$ values for the main effects are also presented in the table. Duncan post hoc tests indicate that the effect of string length on

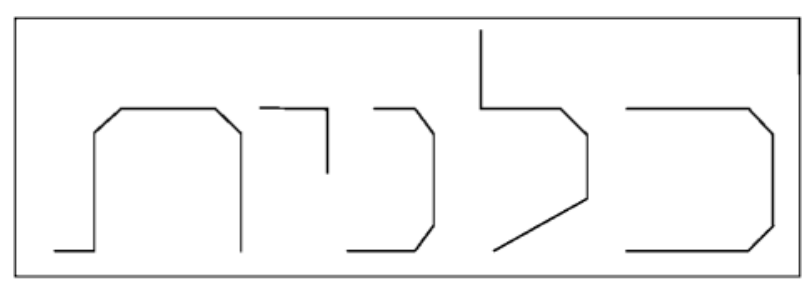

A

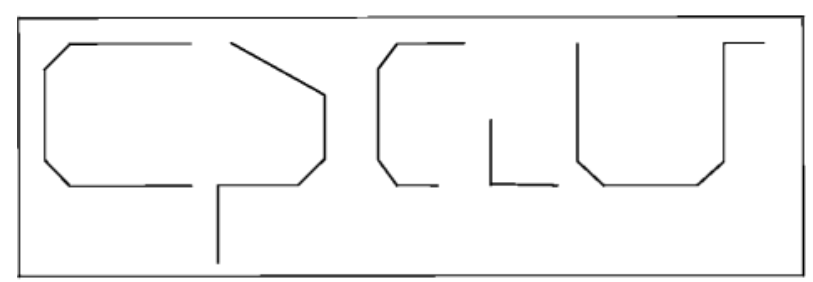

B

Figure 2. Examples of stimuli used. Panel A presents an upright word with no reflected letter. Panel $B$ presents an inverted word with one letter reflected (the second from the left). 
Table 1

Median Latencies (in Milliseconds) and Error Percentages (\% Error) for the Levels of All Factors in Experiment 1, and $F$ and $p$ Values for the Main Effects of the Factors

\begin{tabular}{|c|c|c|}
\hline Factor & Latency & $\%$ Error \\
\hline \multicolumn{3}{|l|}{ Orientation } \\
\hline $0^{\circ}$ & 1,231 & 3.9 \\
\hline $180^{\circ}$ & 2,235 & 7.7 \\
\hline$F$ & 192.51 & 52.59 \\
\hline$p$ & $<.0001$ & $<.0001$ \\
\hline \multicolumn{3}{|l|}{ Reflection } \\
\hline Absent & 1,582 & 4.7 \\
\hline Present & 1,884 & 6.9 \\
\hline$F$ & 131.32 & 20.79 \\
\hline$p$ & $<.0001$ & $<.0001$ \\
\hline \multicolumn{3}{|l|}{ Lexicality } \\
\hline Word & 1,361 & 7.5 \\
\hline Nonword & 2,105 & 4.1 \\
\hline$F$ & 64.32 & 9.93 \\
\hline$p$ & $<.0001$ & $<.005$ \\
\hline \multicolumn{3}{|l|}{ String length } \\
\hline 4 & 1,559 & 7.1 \\
\hline 5 & 1,675 & 5.1 \\
\hline 6 & 1,816 & 5.7 \\
\hline 7 & 1,883 & 5.3 \\
\hline$F$ & 98.71 & 6.37 \\
\hline$p$ & $<.0001$ & $<.001$ \\
\hline \multicolumn{3}{|l|}{ Position } \\
\hline 1 & 2,018 & 7.4 \\
\hline 2 & 1,963 & 7.3 \\
\hline 3 & 1,953 & 7.3 \\
\hline 4 & 1,894 & 5.6 \\
\hline$F$ & 6.24 & 2.25 \\
\hline$p$ & $<.001$ & $>.09$ \\
\hline
\end{tabular}

latency is due to the differences between all the levels and that there is no clear locus for the source of the effect of position on latency. The effect of string length on accuracy is due to a difference between four-letter strings and all the other string lengths.

Figure 3 presents median latency and error percentages as a function of orientation and reflection. The interaction between these two factors was found to be significant for latency $\left[F(1,31)=19.05, M S_{\mathrm{e}}=62,641\right.$, $p<.0001]$ but not for error proportion $(F<1)$. Further tests on latency performed within the two orientations indicated that reflection had significant effects in both $0^{\circ}$ $\left[F(1,31)=119.22, M S_{\mathrm{e}}=147,516, p<.0001\right]$ and $180^{\circ}$ $\left[F(1,31)=75.13, M S_{\mathrm{e}}=93,376, p<.0001\right]$ orientations. Thus, reflection affects the reading of inverted stimuli, contrary to the prediction of the ICO hypothesis.

All other results of the first ANOVA model are presented, along with some comments, in Appendix A, since they are not quite diagnostic for the issue tested here. The second ANOVA was applied only to trials in which the string had a reflected letter. Its results are presented, along with some comments, in Appendix B, since they also are not quite diagnostic for the issue tested here.

All in all, the results of this experiment do not confirm the main prediction of the ICO hypothesis: Reflection does affect the processing of inverted stimuli.

\section{EXPERIMENT 2}

In Experiment 1, we used lexical decision to study whether or not recognition of inverted words is affected by reflection of a letter. Conversely, the purpose of Experiment 2 was to test the ICO hypothesis by studying how word recognition affects reflection judgment.

It is common wisdom that judging reflection on disoriented letters cannot be done very well without some operation of correction, prevalently believed to be mental rotation (see, e.g., Cooper \& Shepard, 1973; Corballis, 1982). The reason is probably that the information required for that judgment is orientation dependent and, hence, is not available when the letter is inverted. However, that deficit can be compensated by way of anticipation of the exact appearance of the nonreflected letter (effected either by its prior presentation or by information presented well in advance about both the identity and the specific orientation of the letter; see, e.g., Cooper \& Shepard, 1973). It thus makes sense that reflection of an inverted letter could be better detected when preceded by the context of an inverted word, provided that the latter afforded complete directional information about its component letters. It could not be better detected if such directional information were missing, as in the case in which orientation-sensitive features were neglected, as the ICO hypothesis posits.

Accordingly, in this experiment the subject was to detect reflection in a specific letter of a word or nonword that was upright or inverted. To eliminate the need to search for the reflected letter, the letter to be judged was indicated to the subjects beforehand. To ensure that the subjects processed entire strings, they were given a task that required string processing and could start the reflection judgment task only on completion of the former task.

Specifically, on each trial the subject was presented with a string with one letter missing and had to make a lexical decision on that string. In order to relieve the patent difficulty of such a task, we had the subject study the words to be presented before the experimental trials started. Immediately after the subject responded, the missing letter was presented and the subject had to judge whether or not it was reflected. We expected that the facilitative effect of the word context would have a chance to be maximally revealed with such a paradigm.

In upright strings, a word context must provide a basis for anticipation about the direction or left-right relationship of the features of a component letter. Most plausibly, such anticipation is provided less, if at all, by a nonword context, since a nonword with a missing letter does not yield any information (except, perhaps, for a slight effect of bigram frequencies computed across strings) about the identity of the missing letter before it is presented for reflection judgment. Actually, this has been confirmed in the experiment itself.

In inverted strings, however, the ICO hypothesis makes a different prediction. According to the ICO hypothesis, a word context, though providing anticipation of the 

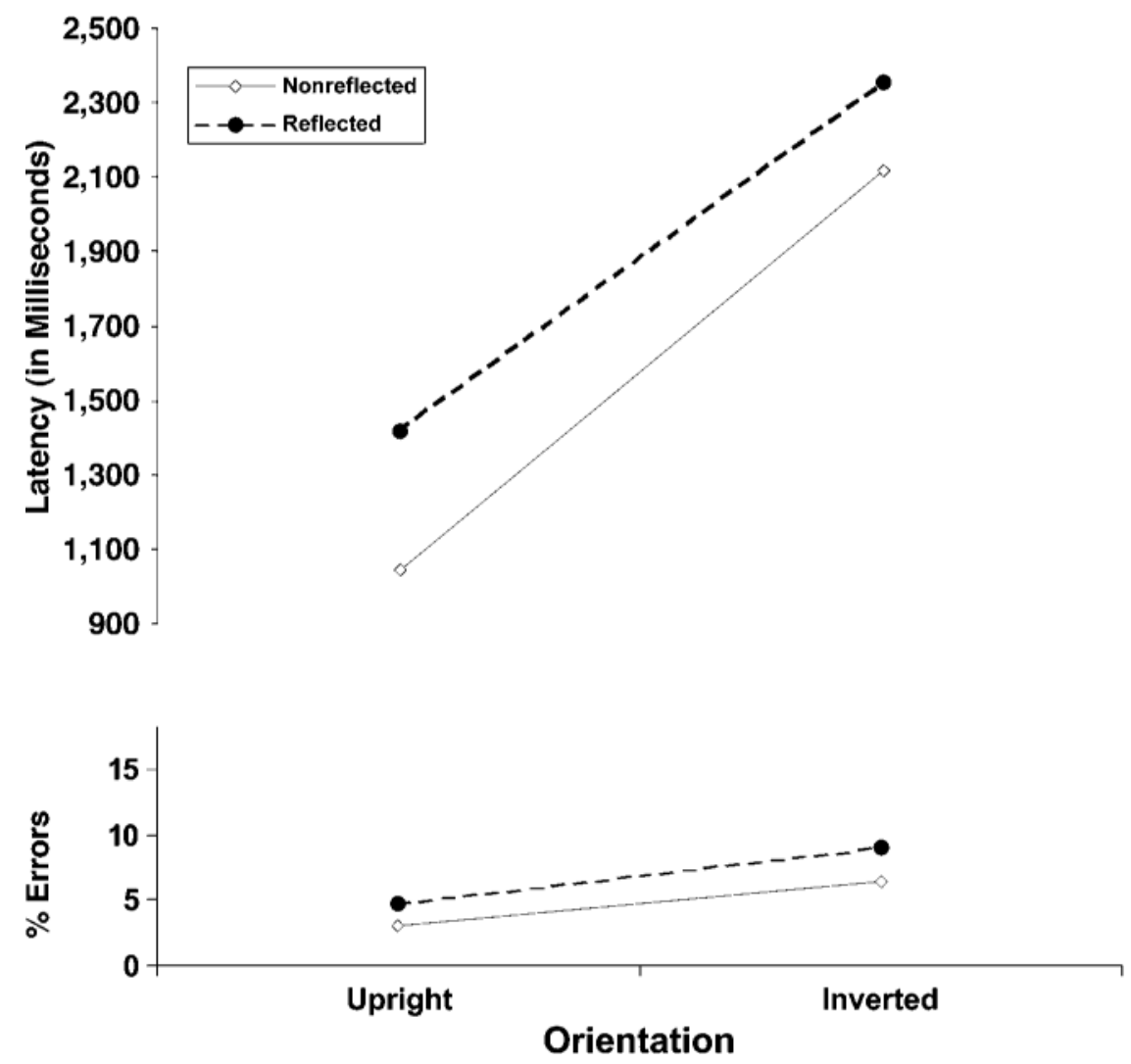

Figure 3. Median latency and error percentages in Experiment 1 as a function of orientation and reflection.

identity of the missing letter before it is presented for reflection judgment, does not provide any anticipation about the left-right relationship of its features. In this respect, a word context does not differ from a nonword context. Hence, an effect of lexicality either would not be found in inverted stimuli or would be much smaller than it would be in upright ones. If, on the other hand, lexicality were about equally effective in both orientations, that would suggest the existence of a rectification of some sort, since rectification enables the use of orientationsensitive features that allows anticipation of the leftright relationship required for determining the presence of reflection in words.

Another factor manipulated is string length. It is not clear whether this factor would interact with lexicality for upright stimuli, considering that the imperative task focuses on just a single letter. Yet the ICO hypothesis has a conditional prediction: If these factors did interact for upright stimuli, the interaction would be smaller for inverted stimuli, since by the ICO hypothesis inverted words do not yield much more response-pertinent information than inverted nonwords do. In contrast, the rectification hypothesis can easily accommodate an absence of that triple interaction.
A third factor is the position of the reflected letter. According to the ICO hypothesis, if position interacted with lexicality for upright stimuli, that interaction would not obtain with inverted stimuli, since inverted words are processed in much the same manner as inverted nonwords are. Again, the rectification hypothesis can easily accommodate an absence of such a triple interaction, although it does not specifically predict it.

\section{Method}

The method was the same as in Experiment 1, except for the following: On each trial a string was presented with a letter missing; the letter was replaced by a dash at the bottom. The instructions were to respond to the lexicality of the string - that is, to indicate by keypressing with the left hand whether it was a word or a nonword. Immediately after the response was given, the whole string was re-presented with the critical letter either reflected or not reflected, and the subject had to indicate which by keypressing with the right hand. Finger-response mapping was counterbalanced across subjects. As in Experiment 1, the position of the critical letter was manipulated as a four-level factor. Before the experiment started, the subjects were given a list of all the words to be used and were asked to study it for about $5 \mathrm{~min}$, since that would help them to perform the task. Otherwise, the procedure, design, apparatus, and stimuli were the same as in Experiment 1. Thirty-two subjects participated in the experiment. All were native Hebrew speakers 
and had normal or corrected-to-normal vision. All were psychology students participating in the experiment for course credit. None had participated in Experiment 1.

\section{Results and Discussion}

Only the performance on the reflection judgment task was analyzed. ANOVAs were performed on cell medians of latencies of correct responses and on arcsine square root transforms of cell proportions of errors.

All data from all of the subjects (excluding data from six trials with mistyped stimuli) were submitted to a four-way analysis (orientation $\times$ position $\times$ string length $\times$ lexicality). Unlike in Experiment 1, here it was possible to include the factor of position in the analysis of all data, for both trials with and trials without a reflected letter, since the position is not of the reflected letter but rather of the letter that was missing in the first phase. In addition, further analyses were performed within levels of some factors that were found to interact with other ones. Results from all analyses are reported here with no reference to their source.

Median latencies and error percentages for all values of all factors are presented in Table 2. $F$ and $p$ values for the main effects are also presented in the table. Duncan post hoc tests indicate that the effect of string length on latency is due to the differences between the four- and five-letter strings and between strings of five and more letters, that the effect of position on latency is due only to the difference between the fourth position and preceding ones, and that there is no clear locus for the source of the effect of position on error proportion.

Figure 4 presents median latencies and error percentages as a function of orientation and lexicality. The interaction between these two factors was found to be significant for both latency $\left[F(1,31)=5.01, M S_{\mathrm{e}}=50,810\right.$, $p<.05]$ and error percentage $\left[F(1,31)=4.69, M S_{\mathrm{e}}=\right.$ $0.0282, p<.05]$.

The triple interaction of position, orientation, and lexicality was marginally significant for latency $[F(3,93)=$ 2.73, $\left.M S_{\mathrm{e}}=53,265, p=.048\right]$ and nonsignificant for error proportion $(F<1)$. The interaction between position and lexicality was significant for latency $[F(3,45)=$ $\left.17.66, M S_{\mathrm{e}}=49,561, p<.0001\right]$ but not for error proportion $\left[F(3,93)=1.35, M S_{\mathrm{e}}=0.059, p>.25\right]$.

The triple interaction of string length, orientation, and lexicality was not significant either for latency $[F(3,93)=$ $\left.1.82, M S_{\mathrm{e}}=48,773, p>.10\right]$ or for error proportion $(F<1)$. Likewise, no other interaction with string length was significant, except for the pairwise interaction between string length and orientation in error proportion $\left[F(3,93)=3.63, M S_{\mathrm{e}}=0.0235, p<.05\right]$. All other results of the ANOVA, along with some comments, are presented in Appendix C, since they are not quite diagnostic for the issue tested here.

Overall, the predictions from the ICO hypothesis have not quite been borne out. First and foremost, the hypothesis predicts that a lexicality effect will be either absent or much smaller in inverted stimuli than in upright
Table 2

Median Latencies (in Milliseconds) and Error Percentages (\% Error) for the Levels of All Factors in Experiment 2, and $F$ and $\boldsymbol{p}$ Values for the Main Effects of the Factors

\begin{tabular}{lcc}
\hline \multicolumn{1}{c}{ Factor } & Latency & \% Error \\
\hline Orientation & & \\
$0^{\circ}$ & 1,013 & 3.4 \\
$\quad 180^{\circ}$ & 1,272 & 10.9 \\
$F$ & 83.82 & 34.91 \\
$p$ & $<.0001$ & $<.0001$ \\
Lexicality & & \\
$\quad$ Word & 1,024 & 7.0 \\
$\quad$ Nonword & 1,261 & 7.3 \\
$F \quad$ & 85.06 & $<1$ \\
$p$ & $<.0001$ & - \\
String length & & \\
4 & 1,243 & 7.4 \\
5 & 1,148 & 7.2 \\
6 & 1,099 & 7.0 \\
7 & 1,079 & 7.1 \\
$F$ & 41.76 & $<1$ \\
$p$ & $<.0001$ & - \\
Position & & \\
1 & 1,142 & 7.2 \\
2 & 1,159 & 7.0 \\
3 & 1,164 & 7.9 \\
4 & 1,104 & 6.7 \\
$F$ & 5.54 & 2.38 \\
$p$ & $<.01$ & $>.05$ \\
\hline
\end{tabular}

ones. However, the interaction between orientation and lexicality was rather small in latency (a lexicality effect for upright stimuli that was only $22 \%$ larger than the corresponding effect in inverted stimuli) and was not in the predicted direction in error proportion. Most important, there was a substantial lexicality effect in inverted stimuli on median latency $(215 \mathrm{msec})$. One might contend that lexicality was confounded here with preexposure. ${ }^{5}$ Actually, however, that deliberate confound (meant to increase the likelihood that word context serves as a clue for the missing letter and hence facilitates the manifestation of a lexicality effect) should not have compromised the validity of this particular test: Even if the superior information about the letter (i.e., anticipation about left-right relationship) in word trials was due solely to preexposure, ex hypothesi that could have an effect in upright stimuli, and much less of an effect in inverted ones.

Second, the triple interaction of orientation $\times$ lexicality $X$ position had only a small and marginally significant effect on latency. A simple pairwise interaction of position $\times$ lexicality was found for inverted stimuli $[F(3,93)=$ $\left.12.45, M S_{\mathrm{e}}=68,780, p<.0001\right]$ and for upright stimuli $\left[F(3,93)=4.83, M S_{\mathrm{e}}=34,046, p<.005\right]$ alike. In addition, when word context was the focus, a simple effect of position was found for inverted words $[F(3,93)=9.32$, $\left.M S_{\mathrm{e}}=69,840, p<.0001\right]$ and for upright words $[F(3,93)=$ $\left.17.43, M S_{\mathrm{e}}=24,706, p<.0001\right]$ alike. All these findings are incompatible with the ICO hypothesis, which predicts a smaller effect in inverted stimuli. The position effect on error proportion did interact with orientation, but 

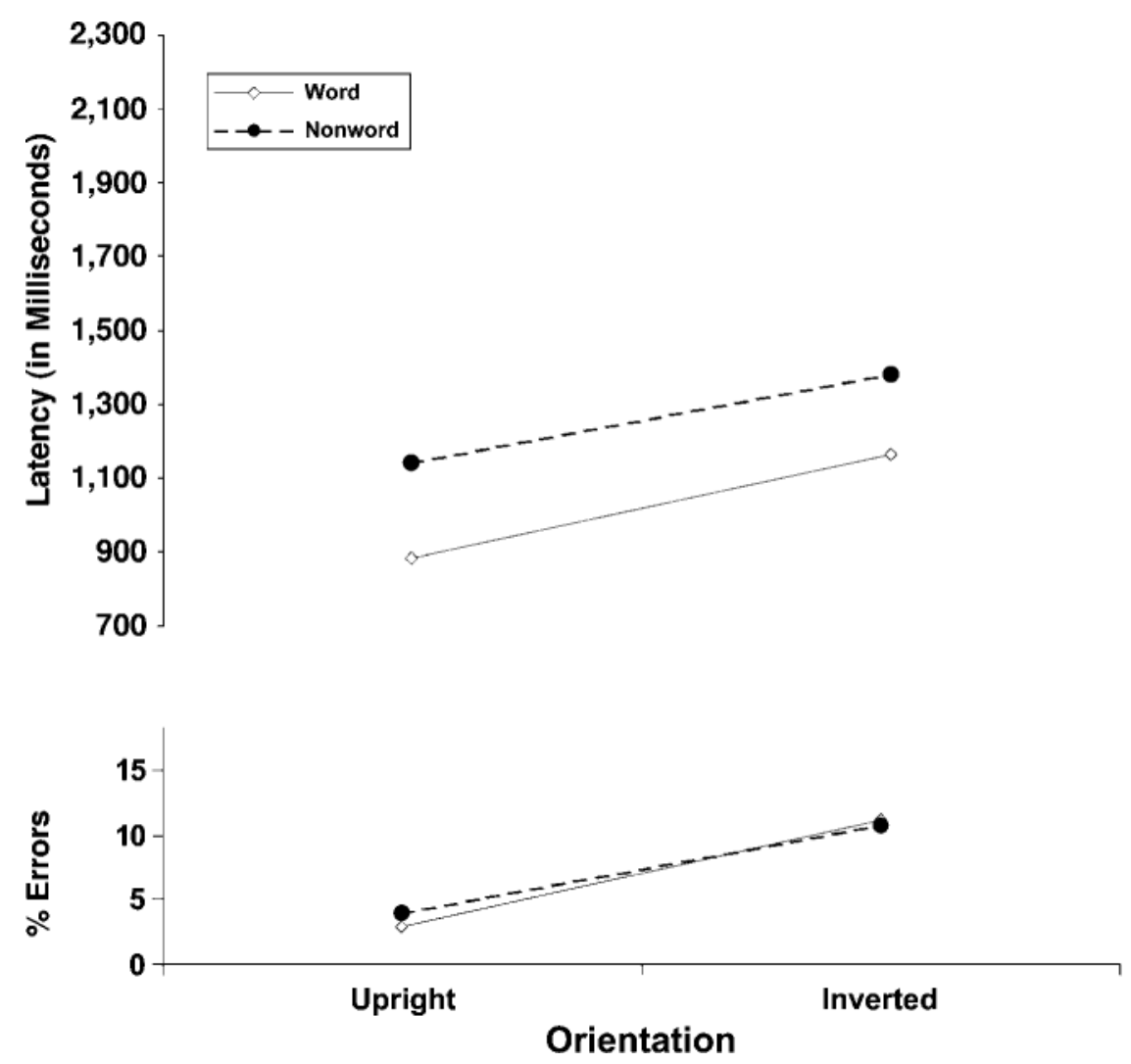

Figure 4. Median latency and error percentages in Experiment 2 as a function of orientation and lexicality.

its locus is present solely in inverted stimuli. This is hard to reconcile with the ICO hypothesis, which assumes no advantage from context for inverted stimuli.

Finally, there was no significant triple interaction of orientation $\times$ lexicality $\times$ string length. Although this appears to be incompatible with the ICO hypothesis, since the latter posits a qualitative difference between the processing of upright stimuli and that of inverted stimuli, it actually is not, because there was no significant pairwise interaction of string length $\times$ lexicality in the first place. On the other hand, although string length had a main effect on latency, that was not modulated by orientation, as is demonstrated by the absence of a significant interaction between string length and orientation, which is some indication against the ICO hypothesis.

Thus, the results of this experiment do not lend much support to the ICO hypothesis, a fact that seems to strengthen the rectification hypothesis.

\section{GENERAL DISCUSSION}

The results of Experiments 1 and 2 converge to render the ICO hypothesis quite implausible. Were inverted words recognized only by orientation-invariant letter features, the recognition of inverted words would not be af- fected by the reflection of a letter, nor would reflection judgments be facilitated by word context.

The finding that the presence of a reflected letter affects lexical decision on inverted stimuli (as in Experiment 1) suggests that inverted words are identified in a way that takes into account some cues in addition to orientation-invariant letter features. Reflection would not have mattered if only such features were used for that process of identification. Thus, some orientationsensitive features are available to exert some effect. Most plausibly, rectification seems to be attempted. True, the effect of reflection is larger for upright stimuli, which suggests that rectification might not be complete. The important point, however, is that some rectification is probably accomplished.

The finding that a word context greatly facilitates reflection judgment in both orientations (Experiment 2) suggests that the former affords not only information about the identity of the probe letter but also some expectancy about its exact direction-dependent appearance derived from information stored in memory about the word's shape. Violation of that expectancy serves as a strong clue about the presence of reflection. That conclusion follows, since mere expectancy about letter identity and direction would probably not be enough. When 
advance cues informing the subject about these two properties separately have been used in mental rotation studies, the extent to which they facilitated reflection judgment (with respect to orientation information only) depended on angular deviation from the upright (see, e.g., Cooper \& Shepard, 1973). Here, however, the lexicality effect was basically the same in both orientations. Furthermore, the facilitative effect of advance information is slow to build up (about $1 \mathrm{sec}$ to offset a $180^{\circ}$ effect), too slow perhaps to benefit the task used in Experiment 2.

The effect of lexicality on reflection judgment observed here confirms what might be suspected: that identification of other letters in the word, and perhaps detection of other word features as well, somehow facilitates processes through which information pertinent to the direction of letter features is computed or retrieved. ${ }^{6}$ The fact that the facilitation is not affected by orientation suggests that inverted words are processed in a manner akin to the processing of upright words, as far as orientation-sensitive information is concerned. That is incompatible with the ICO hypothesis.

By the same token, the similarity of the effects of string length and, to a lesser extent, of the interactive effects of lexicality with string length in $0^{\circ}$ and $180^{\circ}$ orientations suggests that some operation helps to apply to inverted words an identification procedure that is basically similar to the one by which upright words are identified-namely, a rectification operation. That operation itself must take a considerable amount of time, which is probably the source of the main effect of orientation. More generally, although orientation has a sizable main effect, it does not seem to interact with other factors in any dramatic manner. The results thus seem to lend some support to the conclusion that inverted strings are probably rectified before being identified (or coded) or intertwined with it.

What else can be concluded about the nature of that operation? Although this study has not been devised to examine this question systematically, the results have some implications for the possible alternatives. The fact that orientation was not found to interact with string length in Experiment 2 might suggest that the process is global. That is compatible, for one, with a model of analog mental rotation applied to the whole string, but it is compatible as well with the notion of a digital operation that multiplies the coordinates of all stimulus elements in a Cartesian vector representation by -1 . Conceivably, the rectification process, rather than being a sort of normalization of input, amounts to readjustment of the testnamely, a general correction of perceptual schemata. That might lead to a global rectification, albeit one that is understandably costly and not error proof, in processing of inverted words. Inverted nonwords, having no corresponding schemata, would be processed just as they are when upright: in a letter-by-letter fashion.

On the other hand, an orientation $\times$ string length interaction was observed in Experiment 1. That effect on the speed of lexical decision is not necessarily due to a rec- tification process; it could as well be due to a letter-byletter encoding process of inverted stimuli. However, some other effects - prominently lexicality and position in Experiment 1-were found to differ to some extent in the two orientations. It is thus alternatively possible that rectification is applied in a piecemeal fashion, possibly on a letter-by-letter basis. On the arguable assumption that letter recognition does not require any normalization (see, e.g., Corballis \& Nagourney, 1978; but see Jordan \& Huntsman, 1995) - at least not for cursory identification (Corballis, 1988) — one might doubt that mental rotation is needed for a letter-by-letter process. In any event, any hypothesis that posits such a piecemeal process, regardless of whether or not its first stage involves letter normalization, would require a letter reordering process at its second stage. That implies two separate length-sensitive stages in processing inverted stringsthe duration of the first, probably linear in string length, and the duration of the second, possibly quadratic in string length - entailing considerable sensitivity to string length. Such a claim does not seem to be warranted by the present evidence.

Since orientation was found to interact somewhat with some other sources of variance, yet by and large the interactions were far from dramatic, further research is evidently required to explore the properties of the rectification process.

Finally, note that the ICO hypothesis is not the only conceivable hypothesis to assume identification by invariant cues only. People can with effort identify words or read texts transformed in other ways (e.g., reflection about either of the principal axes) and practice these skills quite effectively (Cohen \& Squire, 1980), though probably in a predominantly stimulus-specific manner (Masson, 1986). Although ICO concerns just the processing of inverted script, analogous claims can be made about processing of script transformed in any other way.

For example, to formulate hypotheses about identification of reflected words it makes sense to consider word recognition cues as consisting of three sorts: (1) those that are invariant over all transformations, (2) those that are sensitive to reversal about the horizontal axis, and (3) those that are sensitive to reversal about the vertical axis. The ICO hypothesis claims that inverted words are identified by cues of Subset 1 only, but it is mute with respect to identification of words transformed in other ways. Possibly, words reflected about the vertical axis are identified by cues of Subset 1 and Subset 2, neglecting only cues of Subset 3. By the same token, it is conceivable that words reflected about the horizontal axis are identified by cues of Subset 1 and Subset 3, neglecting only cues of Subset 2 . One might suggest a yet stronger hypothesis positing that there is some overall logic to identification of geometrically transformed texts: Perhaps each transformation triggers the use of the subset of cues that are invariant over it (M. E. J. Masson, personal communication, November 2003). That appears consonant with the finding that different geometric transfor- 
mations lead to substantially different degrees of slowing in reading time (see, e.g., Kolers, 1968).

The present results cast doubt on the ICO hypothesis, and thereby indirectly on the latter, strong hypothesis as well. However, it is still possible that words reflected about just a single axis are identified by their particular subset of invariant features. This may be true of either of the axes or of both. These hypotheses could be an interesting subject for future research.

\section{REFERENCES}

Adams, M. J. (1979). Models of word recognition. Cognitive Psychology, 11, 133-176.

ALLPORT, D. A. (1977). On knowing the meaning of words we are unable to report: The effects of visual masking. In S. Dornic (Ed.), Attention and performance VI (pp. 505-533). Hillsdale, NJ: Erlbaum.

AnNetT, M. (1991). Reading upside down and mirror text in groups differing for right minus left hand skill. European Journal of Cognitive Psychology, 3, 363-377.

Bentin, S., \& Frost, R. (1987). Processing lexical ambiguity and visual word recognition in a deep orthography. Memory \& Cognition, 15, 13-23.

BeSNer, D., DavelaAr, E., Alcott, D., \& Parry, P. (1984). Wholistic reading of alphabetic print: Evidence from the FDM and the FBI. In L. Henderson (Ed.), Orthographies and reading: Perspectives from cognitive psychology, neuropsychology, and linguistics (pp. 121135). Hove, U.K.: Erlbaum.

Cohen, N. J., \& SQuire, L. R. (1980). Preserved learning and retention of pattern-analyzing skill in amnesia: Dissociation of knowing how and knowing that. Science, 210, 207-210.

COOPER, L. A. (1975). Mental transformations of random two-dimensional shapes. Cognitive Psychology, 7, 20-43.

COOPER, L. A., \& PODGORNY, P. (1976). Mental transformations and visual comparison processes: Effects of complexity and similarity. Journal of Experimental Psychology: Human Perception \& Performance, 2, 503-514.

CoOper, L. A., \& SHEPARD, R. N. (1973). Chronometric studies of the rotation of mental images. In W. G. Chase (Ed.), Visual information processing (pp. 75-176). New York: Academic Press.

Corballis, M. C. (1982). Mental rotation: Anatomy of a paradigm. In M. Potegal (Ed.), Spatial abilities: Development and physiological foundations (pp. 173-197). New York: Academic Press.

Corballis, M. C. (1988). Recognition of disoriented shapes. Psychological Review, 95, 115-123.

Corballis, M. C., \& NAGOURNey, B. A. (1978). Latency to categorize disoriented alphanumeric characters as letters or digits. Canadian Journal of Psychology, 32, 186-188.

Corballis, M. C., Zbrodoff, N. J., Shetzer, L. I., \& Butler, P. B. (1978). Decisions about identity and orientation of rotated letters and digits. Memory \& Cognition, 6, 98-107.

Dechant, E. V., \& Smith, H. P. (1977). Psychology in teaching reading. Englewood Cliffs, NJ: Prentice-Hall.

Driver, J., \& BAYLIS, G. C. (1995). Tilted letters and tilted words: A possible role for principal axes in visual word recognition. Memory \& Cognition, 23, 560-568.

ELEY, M. G. (19 $\overline{82}$ ). Identifying rotated letter-like symbols. Memory \& Cognition, 10, 25-32.

FreDERIKSEN, J. R., \& Kroll, J. F. (1976). Spelling and sound: Approaches to the internal lexicon. Journal of Experimental Psychology: Human Perception \& Performance, 2, 361-379.

Gibson, B. S., \& Peterson, M. A. (1994). Does orientation-independent object recognition precede orientation-dependent recognition? Evidence from a cuing paradigm. Journal of Experimental Psychology: Human Perception \& Performance, 20, 299-316.

HENDERSON, L. (1982). Orthography and word recognition in reading. London: Academic Press.

Hochberg, J., \& Gellman, L. (1977). The effect of landmark features on "mental rotation" times. Memory \& Cognition, 5, 23-26.
JOHNSON, N. F. (1975). On the function of letters in word identification: Some data and a preliminary model. Journal of Verbal Learning \& Verbal Behavior, 14, 17-29.

JoHnson, N. F. (1981). Integration processes in word recognition. In O. J. L. Tzeng \& H. Singer (Eds.), Perception of print: Reading research in experimental psychology (pp. 29-63). Hillsdale, NJ: Erlbaum.

Jolicceur, P., \& Humphrey, G. K. (1998). Perception of rotated twodimensional and three-dimensional objects and visual shapes. In V. Walsh \& J. Kulikowski (Eds.), Perceptual constancy: Why things look as they do (pp. 69-123). New York: Cambridge University Press.

Joliceeur, P., \& Landau, M. J. (1984). Effects of orientation on the identification of simple visual patterns. Canadian Journal of Psychology, 39, 100-129.

JolicceUR, P., \& MiLLIKen, B. (1989). Identification of disoriented objects: Effects of context of prior presentation. Journal of Experimental Psychology: Learning, Memory, \& Cognition, 15, 200-210.

JORDAN, K., \& HUNTSMAN, L. A. (1990). Image rotation of misoriented letter strings: Effects of orientation cuing and repetition. Perception \& Psychophysics, 48, 363-374.

JoRDAN, K., \& HUNTSMAN, L. A. (1995). Repetition of misoriented words reduces lexical-decision response times at repeated and novel orientations. Journal of Experimental Psychology: Human Perception \& Performance, 12, 963-977.

Kolers, P. A. (1968). The recognition of geometrically transformed text. Perception \& Psychophysics, 3, 57-64.

Kolers, P. A., \& Perkins, D. N. (1969a). Orientation of letters and errors in their recognition. Perception \& Psychophysics, 5, 265-269.

Kolers, P. A., \& Perkins, D. N. (1969b). Orientation of letters and their speed of recognition. Perception \& Psychophysics, 5, 275-280.

Kolers, P. A., \& Perkins, D. N. (1975). Spatial and ordinal components of form perception and literacy. Cognitive Psychology, 7, 228-267.

Koriat, A., \& Norman, J. (1984). What is rotated in mental rotation? Journal of Experimental Psychology: Learning, Memory, \& Cognition, 10, 421-434.

KoRIAT, A., \& NORMan, J. (1985). Reading rotated words. Journal of Experimental Psychology: Human Perception \& Performance, 11, 490-508.

Koriat, A., \& Norman, J. (1988). Frames and images: Sequential effects in mental rotation. Journal of Experimental Psychology: Learning, Memory, \& Cognition, 14, 93-111.

KoRIAT, A., \& NoRman, J. (1989). Why is word recognition impaired by disorientation while the identification of single letters is not? Journal of Experimental Psychology: Human Perception \& Performance, 15, 153-163.

LARSEN, S., \& PARLENVI, P. (1984). Patterns of inverted reading and subgroups of dyslexia. Annals of Dyslexia, 34, 195-203.

MarR, D., \& NishiHara, H. K. (1978). Representation and recognition of the spatial organization of three-dimensional shapes. Proceedings of the Royal Society of London: Series B, 200, 269-294.

MAsson, M. E. J. (1986). Identification of typographically transformed words: Instance-based skill acquisition. Journal of Experimental Psychology: Learning, Memory, \& Cognition, 12, 479-488.

MCClelland, J. L., \& Rumelhart, D. E. (1981). An interactive activation model of context effects in letter perception: Part 1. An account of basic findings. Psychological Review, 88, 375-407.

McMullen, P. A., \& Jolicceur, P. (1990). The spatial frame of reference in object naming and discrimination of left-right reflections. Memory \& Cognition, 18, 99-115.

NAVON, D. (1978). Perception of misoriented words and letter strings. Canadian Journal of Psychology, 32, 129-140.

NAvon, D., \& Shimron, J. (1981). Does word naming involve grapheme-to-phoneme translation? Evidence from Hebrew. Journal of Verbal Learning \& Verbal Behavior, 20, 97-109.

Navon, D., \& Shimron, J. (1984). Reading Hebrew: How necessary is the graphemic representation of vowels? In L. Henderson (Ed.), Orthographies and reading: Perspectives from cognitive psychology, neuropsychology, and linguistics (pp. 91-102). Hove, U.K.: Erlbaum.

PaAp, K. R., Newsome, S. L., McDonald, J. E., \& SchvaneVELDT, R. W. (1982). An activation-verification model for letter and word recognition: The word-superiority effect. Psychological Review, 89, 573-594.

PARKS, T. E. (1983). Letter to the editor. Perception, 12, 88. 
Pringle, R., \& Cowan, T. M. (1978). Mental rotation of possible and impossible four-cornered toruses. Perception \& Psychophysics, 24, 84-92.

PyLyshyn, Z. W. (1979). The rate of "mental rotation" of images: A test of a holistic analogue hypothesis. Memory \& Cognition, 7, 19-28.

Raveh, O. (1990). Processes in upside-down word recognition. Unpublished master's thesis, University of Haifa.

RAYNER, K. (1983). Eye movements, perceptual span and reading disability. Annals of dyslexia, 33, 163-173.

Rock, I. (1973). Orientation and form. New York: Academic Press.

Shepard, R. N., \& Cooper, L. A. (1982). Mental images and their transformations. Cambridge, MA: MIT Press.

Shepard, R. N., \& Metzler, J. (1971). Mental rotation of threedimensional objects. Science, 171, 701-703.

SuEN, C. Y. (1986). Character recognition by computer and applications. In T. Y. Young \& K. Fu (Eds.), Handbook of pattern recognition and image processing (pp. 569-586). San Diego: Academic Press.

TARr, M. J, \& PINKER, S. (1989). Mental rotation and orientationdependence in shape recognition. Cognitive Psychology, 21, 233282.

White, M. J. (1980). Naming and categorization of tilted alphanumeric characters do not require mental rotation. Bulletin of the Psychonomic Society, 15, 153-156.

Yuille, J. C., \& Steiger, J. H. (1982). Nonholistic processing in mental rotation: Some suggestive evidence. Perception \& Psychophysics, 31, 201-209.

\section{NOTES}

1. There are exceptions, though. In old Jewish schools in Yemen, there were very few books, so that students had to form a circle around a single book. Hearsay has it that people who had learned to read in those schools could read Hebrew in any orientation with equal speed.
2. Curiously, there are indications that some dyslexics and schoolchildren with poor reading ability read better when the text is inverted (Annett, 1991; Larsen \& Parlenvi, 1984; Rayner, 1983).

3. Note that a $180^{\circ}$ rotation is actually tantamount to the composite of two orthogonal reflections: one about the vertical axis, the other about the horizontal one. Hence, by the ICO hypothesis, the identification of inverted words resorts neither to cues sensitive to reflection about the vertical axis nor to ones sensitive to reflection about the horizontal axis.

4. In Hebrew, most vowel information is conveyed by diacritical marks underneath or above the letters. However, most texts are printed without those vowel signs-hence the term unvowelized orthography (see Navon \& Shimron, 1984). Practiced readers can read such texts fluently and can readily recognize unvowelized words that have only one reading (Koriat \& Norman, 1984; Navon \& Shimron, 1981) as well as unvowelized words that have more than one reading in the case in which the more frequent reading is intended (Bentin \& Frost, 1987).

5. That seems implausible. In the study on which this paper follows (Raveh, 1990), both words and nonwords were either primed shortly before exposure (for half of the subjects) or not preexposed at all (for the other half); no hint of an interaction between lexicality and orientation was present in either of the groups.

6 . That follows from the premise that word representations in memory involved in word recognition contain rich visual information, including spatial relationships between adjacent letters, which are possibly supraletter features. Although some influential theories of word recognition (see, e.g., Adams, 1979; Henderson, 1982; McClelland \& Rumelhart, 1981; Paap, Newsome, McDonald, \& Schvaneveldt, 1982) downplay the role of such information in word recognition per se (but see, e.g., Allport, 1977; Besner, Davelaar, Alcott, \& Parry, 1984; Dechant \& Smith, 1977; Johnson, 1975, 1981), it seems hard to dispute that spatial relationships between letters can at least be readily computed from the information that is explicit in the representations. 
APPENDIX A

Results of the First ANOVA in Experiment 1

Median latencies and error percentages in Experiment 1 as a function of lexicality, string length, orientation, and reflection are presented in Table A1.

Table A1

Median Latencies (in Milliseconds) and Error Percentages in Experiment 1 as a Function of Lexicality, String Length, Orientation, and Reflection

\begin{tabular}{|c|c|c|c|c|c|c|c|c|}
\hline \multirow[b]{3}{*}{ Lexicality } & \multirow{3}{*}{$\begin{array}{l}\text { String } \\
\text { Length }\end{array}$} & \multicolumn{6}{|c|}{ Orientation } & \multirow[b]{3}{*}{$\bar{M}$} \\
\hline & & \multicolumn{3}{|c|}{ Upright } & \multicolumn{3}{|c|}{ Inverted } & \\
\hline & & Reflected & Nonreflected & $M$ & Reflected & Nonreflected & $M$ & \\
\hline & \multicolumn{8}{|c|}{ Median Latency } \\
\hline \multirow[t]{4}{*}{ Word } & 4 & 998 & 794 & 896 & 1,673 & 1,370 & 1,522 & 1,209 \\
\hline & 5 & 924 & 814 & 869 & 1,831 & 1,546 & 1,689 & 1,279 \\
\hline & 6 & 993 & 822 & 908 & 2,068 & 1,793 & 1,931 & 1,420 \\
\hline & 7 & 1,017 & 863 & 940 & 2,279 & 1,994 & 2,137 & 1,539 \\
\hline$M$ & & 983 & 823 & 903 & 1,963 & 1,676 & 1,820 & 1,362 \\
\hline \multirow[t]{4}{*}{ Nonword } & 4 & 1,842 & 1,248 & 1,545 & 2,376 & 2,172 & 2,274 & 1,910 \\
\hline & 5 & 1,855 & 1,201 & 1,528 & 2,705 & 2,519 & 2,612 & 2,070 \\
\hline & 6 & 1,872 & 1,261 & 1,567 & 2,936 & 2,782 & 2,859 & 2,213 \\
\hline & 7 & 1,832 & 1,365 & 1,599 & 2,949 & 2,769 & 2,859 & 2,229 \\
\hline$M$ & & 1,850 & 1,269 & 1,559 & 2,742 & 2,561 & 2,651 & 2,105 \\
\hline \multirow[t]{2}{*}{$\bar{M}$} & & 1,417 & 1,046 & 1,231 & 2,353 & 2,118 & 2,236 & \\
\hline & \multicolumn{8}{|c|}{ Error Percentage } \\
\hline \multirow[t]{4}{*}{ Word } & 4 & 8.00 & 2.93 & 5.47 & 11.33 & 8.36 & 9.85 & 7.66 \\
\hline & 5 & 4.88 & 3.52 & 4.20 & 12.49 & 6.62 & 9.56 & 6.88 \\
\hline & 6 & 4.63 & 2.15 & 3.39 & 17.38 & 8.20 & 12.79 & 8.09 \\
\hline & 7 & 4.28 & 2.73 & 3.51 & 13.28 & 9.79 & 11.54 & 7.52 \\
\hline$M$ & & 5.45 & 2.83 & 4.14 & 13.62 & 8.24 & 10.93 & 7.54 \\
\hline \multirow[t]{4}{*}{ Nonword } & 4 & 6.65 & 4.69 & 5.67 & 7.44 & 7.23 & 7.34 & 6.50 \\
\hline & 5 & 2.54 & 3,12 & 2.54 & 3.43 & 4.30 & 3.87 & 3.20 \\
\hline & 6 & 3.34 & 1.95 & 2.65 & 3.73 & 4.17 & 3.95 & 3.30 \\
\hline & 7 & 3.32 & 3.33 & 3.33 & 3.52 & 2.54 & 3.03 & 3.18 \\
\hline$M$ & & 3.96 & 3.32 & 3.55 & 4.53 & 4.56 & 4.55 & 4.05 \\
\hline $\bar{M}$ & & 4.71 & 3.08 & 3.84 & 9.08 & 6.40 & 7.74 & \\
\hline
\end{tabular}

Further Comments

The interaction between lexicality and reflection was significant for both latency $\left[F(1,31)=18.00, M S_{\mathrm{e}}=\right.$ $88,375, p<.0002]$ and error proportion $\left[F(1,31)=24.60, M S_{\mathrm{e}}=0.01687, p<.0001\right]$. That interaction may be due to the greater dependence of nonword coding on the identification of all letters. Word recognition can probably tolerate deviations in the form of a letter thanks to activation from the other letters and the word code itself (see McClelland \& Rumelhart, 1981). Another possible account is that the locus of the effect is in postperceptual processes: When subjects notice the reflection in a nonword, they might suspect that the lack of familiarity with the stimulus is actually due not to its lexical status but rather to its deviation from the familiar form of the word. That leads to further checks, or deliberations, which take some time.

The triple interaction of lexicality $\times$ orientation $\times$ reflection was significant for latency $[F(1,31)=71.11$, $\left.M S_{\mathrm{e}}=62,711, p<.0001\right]$ and error proportion $\left[F(1,31)=6.39, M S_{\mathrm{e}}=0.01071, p<.02\right]$. Further tests on latency indicated that the pairwise interaction of lexicality $\times$ reflection showed a strong and significant effect for upright stimuli $\left[F(1,31)=63.59, M S_{\mathrm{e}}=89,591, p<.0001\right]$ and a smaller effect for inverted ones $\left[F(1,31)=5.81, M S_{\mathrm{e}}=61,854, p<.03\right]$. Reflection seems to delay the coding of upright nonwords more than the recognition of upright words (delays of $589 \mathrm{vs} .160 \mathrm{msec}$ ), an effect that was not quite matched by inverted stimuli (delays of $267 \mathrm{vs} .181 \mathrm{msec}$ ). Conceivably, the sort of postperceptual checks possibly induced by reflection within an upright nonword are needed in any case for processing any inverted stimulus, so that an inverted nonword is not more affected by reflection than an inverted word is.

The interaction between orientation and lexicality was significant for error proportion $[F(1,31)=23.51$, $\left.M S_{\mathrm{e}}=0.04263, p<.0001\right]$ and, to a smaller extent, for latency $\left[F(1,31)=6.71, M S_{\mathrm{e}}=293,288, p<.02\right]$. The reason for the interaction in the accuracy measure is that inverted words were often mistaken for nonwords. It appears as though this happened more when a letter was reflected, but there is no statistically significant support for this. The interaction in latency is quite small (a lexicality effect for inverted stimuli that was $26 \%$ larger than the corresponding one for upright stimuli). Furthermore, the effect of lexicality is substantial (a 831-msec delay) and significant for inverted stimuli. 
APPENDIX A (Continued)

The triple interaction of the factors of lexicality, orientation, and string length was significant for latency $\left[F(3,93)=3.44, M S_{\mathrm{e}}=53,417, p>.02\right]$ but not for error proportion $\left[F(3,93)=2.17, M S_{\mathrm{e}}=0.02156, p>\right.$ .10]. Of the three pairwise interactions of those factors, orientation $\times$ string length was significant for latency $\left[F(3,93)=57.08, M S_{\mathrm{e}}=68,627, p<.0001\right]$ and lexicality $\times$ string length was significant for latency $[F(3,93)=$ $\left.3.64, M S_{\mathrm{e}}=55,511, p>.02\right]$ and for error proportion $\left[F(3,93)=6.37, M S_{\mathrm{e}}=0.01832, p<.0006\right]$.

On the other hand, although for upright stimuli string length did not affect latency at all, its effect was sizable for inverted stimuli. The apparently serial process could be a letter-by-letter coding process as well as a rectification process.

\section{APPENDIX B \\ Results of the Second ANOVA in Experiment 1}

In Table B1, median latencies and error percentages in Experiment 1 as a function of position, string length, orientation, and lexicality are presented only for trials in which the string had a reflected letter.

Table B1

Median Latencies (in Milliseconds) and Error Percentages in Experiment 1 as a Function of Position, String Length, Orientation, and Lexicality for Trials in Which the String Had a Reflected Letter

\begin{tabular}{|c|c|c|c|c|c|c|c|c|}
\hline \multirow[b]{3}{*}{ Position } & \multirow{3}{*}{$\begin{array}{l}\text { String } \\
\text { Length }\end{array}$} & \multicolumn{6}{|c|}{ Orientation } & \multirow[b]{3}{*}{$\bar{M}$} \\
\hline & & \multicolumn{3}{|c|}{ Upright } & \multicolumn{3}{|c|}{ Inverted } & \\
\hline & & Word & Nonword & $M$ & Word & Nonword & $M$ & \\
\hline & \multicolumn{8}{|c|}{ Median Latency } \\
\hline \multirow[t]{4}{*}{1} & 4 & 1,058 & 1,982 & 1,520 & 1,793 & 2,451 & 2,122 & 1,821 \\
\hline & 5 & 980 & 2,134 & 1,557 & 1,806 & 2,631 & 2,219 & 1,888 \\
\hline & 6 & 1,068 & 2,072 & 1,570 & 2,220 & 3,014 & 2,617 & 2,094 \\
\hline & 7 & 1,285 & 2,192 & 1,739 & 2,356 & 3,241 & 2,799 & 2,269 \\
\hline$M$ & & 1,098 & 2,095 & 1,596 & 2,044 & 2,834 & 2,439 & 2,018 \\
\hline \multirow[t]{4}{*}{2} & 4 & 988 & 1,906 & 1,447 & 1,814 & 2,738 & 2,276 & 1,862 \\
\hline & 5 & 956 & 1,883 & 1,420 & 1,777 & 2,821 & 2,299 & 1,860 \\
\hline & 6 & 1,090 & 1,988 & 1,539 & 2,062 & 2,998 & 2,530 & 2,035 \\
\hline & 7 & 1,029 & 1,778 & 1,404 & 2,346 & 3,241 & 2,794 & 2,099 \\
\hline$M$ & & 1,016 & 1,889 & 1,452 & 2,000 & 2,950 & 2,475 & 1,964 \\
\hline \multirow[t]{4}{*}{3} & 4 & 1,039 & 1,822 & 1,431 & 1,731 & 2,593 & 2,162 & 1,797 \\
\hline & 5 & 947 & 1,691 & 1,319 & 1,891 & 2,667 & 2,279 & 1,799 \\
\hline & 6 & 1,040 & 1,767 & 1,404 & 2,248 & 2,961 & 2,605 & 2,005 \\
\hline & 7 & 970 & 1,816 & 1,393 & 2,164 & 2,958 & 2,561 & 1,977 \\
\hline$M$ & & 999 & 1,774 & 1,387 & 2,009 & 2,795 & 2,402 & 1,895 \\
\hline \multirow[t]{4}{*}{4} & 4 & 1,073 & 1,954 & 1,514 & 1,631 & 2,375 & 2,003 & 1,759 \\
\hline & 5 & 991 & 1,926 & 1,459 & 2,044 & 3,045 & 2,545 & 2,002 \\
\hline & 6 & 1,068 & 1,885 & 1,477 & 2,092 & 3,061 & 2,577 & 2,027 \\
\hline & 7 & 1,125 & 1,814 & 1,470 & 2,335 & 2,837 & 2,586 & 2,028 \\
\hline$M$ & & 1,064 & 1,895 & 1,480 & 2,026 & 2,830 & 2,428 & 1,954 \\
\hline \multirow[t]{2}{*}{$\bar{M}$} & & 1,044 & 1,913 & 1,479 & 2,020 & 2,852 & 2,436 & \\
\hline & \multicolumn{8}{|c|}{ Error Percentage } \\
\hline \multirow[t]{4}{*}{1} & 4 & 10.94 & 10.16 & 10.55 & 7.81 & 6.25 & 7.03 & 8.79 \\
\hline & 5 & 6.25 & 2.34 & 4.30 & 12.50 & 2.34 & 7.42 & 5.86 \\
\hline & 6 & 5.47 & 6.25 & 5.86 & 9.37 & 3.91 & 6.64 & 6.25 \\
\hline & 7 & 7.03 & 5.47 & 6.25 & 13.28 & 7.03 & 10.16 & 8.20 \\
\hline$M$ & & 7.42 & 6.06 & 6.74 & 10.74 & 4.88 & 7.81 & 7.28 \\
\hline \multirow[t]{4}{*}{2} & 4 & 3.91 & 6.25 & 5.08 & 9.37 & 8.59 & 8.98 & 7.03 \\
\hline & 5 & 3.12 & 0.00 & 1.56 & 14.69 & 2.34 & 8.52 & 5.04 \\
\hline & 6 & 2.34 & 3.12 & 2.73 & 14.84 & 2.34 & 8.59 & 5.66 \\
\hline & 7 & 2.34 & 2.34 & 2.34 & 10.94 & 3.39 & 7.17 & 4.75 \\
\hline$M$ & & 2.93 & 2.93 & 2.93 & 12.46 & 4.17 & 8.31 & 5.62 \\
\hline \multirow[t]{4}{*}{3} & 4 & 6.25 & 5.47 & 5.86 & 14.84 & 9.37 & 12.11 & 8.98 \\
\hline & 5 & 5.47 & 3.90 & 4.69 & 14.06 & 3.12 & 8.59 & 6.64 \\
\hline & 6 & 2.97 & 1.56 & 2.27 & 25.78 & 2.34 & 14.06 & 8.16 \\
\hline & 7 & 1.56 & 2.34 & 1.95 & 16.40 & 1.56 & 8.98 & 5.47 \\
\hline$M$ & & 4.06 & 3.32 & 3.69 & 17.77 & 4.10 & 10.93 & 7.31 \\
\hline
\end{tabular}


APPENDIX B (Continued)

\begin{tabular}{|c|c|c|c|c|c|c|c|c|}
\hline \multicolumn{9}{|c|}{ Table B1 (Continued) } \\
\hline \multirow[b]{3}{*}{ Position } & \multirow{3}{*}{$\begin{array}{l}\text { String } \\
\text { Length }\end{array}$} & \multicolumn{6}{|c|}{ Orientation } & \multirow[b]{3}{*}{$\bar{M}$} \\
\hline & & \multicolumn{3}{|c|}{ Upright } & \multicolumn{3}{|c|}{ Inverted } & \\
\hline & & Word & Nonword & $M$ & Word & Nonword & $M$ & \\
\hline \multirow{4}{*}{4} & 4 & 10.94 & 4.69 & 7.82 & 13.80 & 5.47 & 9.64 & 8.73 \\
\hline & 5 & 4.69 & 3.90 & 4.30 & 8.59 & 5.98 & 7.29 & 5.79 \\
\hline & 6 & 7.82 & 2.34 & 5.08 & 19.53 & 6.25 & 12.89 & 8.99 \\
\hline & 7 & 6.09 & 3.12 & 4.61 & 12.50 & 2.34 & 7.42 & 6.01 \\
\hline$M$ & & 7.39 & 3.51 & 5.45 & 13.61 & 5.01 & 9.31 & 7.38 \\
\hline $\bar{M}$ & & 5.45 & 3.95 & 4.70 & 13.64 & 4.54 & 9.09 & \\
\hline
\end{tabular}

\section{Further Comments}

The interaction between position and orientation was significant for latency $\left[F(3,93)=3.42, M S_{\mathrm{e}}=\right.$ $259,641, p<.03]$ and for error proportion $\left[F(3,93)=3.98, M S_{\mathrm{e}}=0.07222, p<.02\right]$. The simple effect of position for inverted stimuli was not significant for either latency or error proportion. Remember that the ICO hypothesis does not predict any effect of position of the reflected letter for inverted stimuli, since it assumes that reflection is normally not detected in such stimuli. However, since reflection itself has been found to have an effect for inverted stimuli, the absence of a simple effect of position might suggest that rectification does not quite restore the stimulus to its canonic appearance before recognition is attempted.

A triple interaction of lexicality, position, and string length was not found for latency $[F(9,279)=1.20$, $\left.M S_{\mathrm{e}}=226,616, p<.29\right]$ but was significant for error proportion $\left[F(9,279)=2.40, M S_{\mathrm{e}}=0.04673, p<.02\right]$. Position interacted significantly with lexicality for error proportion $\left[F(3,93)=2.76, M S_{\mathrm{e}}=0.05372, p<.05\right]$ but not quite for latency $\left[F(3,93)=2.25, M S_{\mathrm{e}}=217,508, p<.09\right]$.

The triple interaction of orientation, position, and string length was significant for latency $[F(9,279)=$ $\left.2.48, M S_{\mathrm{e}}=236,395, p=.01\right]$ but not for error proportion. No other interaction with position was significant except for the one mentioned in the Results section. The triple interaction of orientation, position, and lexicality only approached significance $\left[F(3,93)=2.60, M S_{\mathrm{e}}=0.05896, p=.057\right]$ for error proportion and, in any case, was minute and hard to interpret even if genuine. 
APPENDIX C

Results of the ANOVA in Experiment 2

Median latencies and error percentages in Experiment 2 as a function of position, string length, orientation, and lexicality are presented in Table $\mathrm{C} 1$.

Table C1

Median Latencies (in Milliseconds) and Error Percentages in Experiment 2 as a Function of Position, String Length, Orientation, and Lexicality

\begin{tabular}{|c|c|c|c|c|c|c|c|c|}
\hline \multirow[b]{3}{*}{ Position } & \multirow{3}{*}{$\begin{array}{l}\text { String } \\
\text { Length }\end{array}$} & \multicolumn{6}{|c|}{ Orientation } & \multirow[b]{3}{*}{$\bar{M}$} \\
\hline & & \multicolumn{3}{|c|}{ Upright } & \multicolumn{3}{|c|}{ Inverted } & \\
\hline & & Word & Nonword & $M$ & Word & Nonword & $M$ & \\
\hline & \multicolumn{8}{|c|}{ Median Latency } \\
\hline \multirow[t]{4}{*}{1} & 4 & 900 & 1,271 & 1,086 & 1,210 & 1,528 & 1,369 & 1,228 \\
\hline & 5 & 838 & 1,130 & 984 & 1,207 & 1,531 & 1,369 & 1,177 \\
\hline & 6 & 838 & 1,096 & 967 & 1,032 & 1,314 & 1,173 & 1,070 \\
\hline & 7 & 801 & 1,112 & 957 & 1,044 & 1,416 & 1,230 & 1,094 \\
\hline$M$ & & 844 & 1,152 & 998 & 1,123 & 1,447 & 1,285 & 1,142 \\
\hline \multirow[t]{4}{*}{2} & 4 & 1,079 & 1,259 & 1,169 & 1,251 & 1,490 & 1,371 & 1,270 \\
\hline & 5 & 924 & 1,191 & 1,058 & 1,201 & 1,302 & 1,252 & 1,155 \\
\hline & 6 & 851 & 1,157 & 1,004 & 1,190 & 1,311 & 1,251 & 1,128 \\
\hline & 7 & 857 & 1,028 & 943 & 1,231 & 1,227 & 1,229 & 1,086 \\
\hline$M$ & & 928 & 1,159 & 1,043 & 1,218 & 1,333 & 1,275 & 1,159 \\
\hline \multirow[t]{4}{*}{3} & 4 & 1,055 & 1,231 & 1,143 & 1,309 & 1,494 & 1,402 & 1,273 \\
\hline & 5 & 916 & 1,074 & 995 & 1,168 & 1,384 & 1,276 & 1,136 \\
\hline & 6 & 956 & 1,149 & 1,053 & 1,259 & 1,274 & 1,267 & 1,160 \\
\hline & 7 & 823 & 1,107 & 965 & 1,185 & 1,232 & 1,209 & 1,087 \\
\hline$M$ & & 938 & 1,140 & 1,039 & 1,230 & 1,346 & 1,288 & 1,164 \\
\hline \multirow{4}{*}{4} & 4 & 947 & 1,170 & 1,059 & 1,203 & 1,499 & 1,351 & 1,205 \\
\hline & 5 & 794 & 1,199 & 997 & 1,063 & 1,439 & 1,251 & 1,124 \\
\hline & 6 & 766 & 1,060 & 913 & 1,030 & 1,296 & 1,163 & 1,038 \\
\hline & 7 & 785 & 1,044 & 915 & 1,045 & 1,328 & 1,187 & 1,051 \\
\hline$M$ & & 823 & 1,118 & 971 & 1,085 & 1,391 & 1,238 & 1,105 \\
\hline \multirow[t]{2}{*}{$\bar{M}$} & & 883 & 1,142 & 1,013 & 1,164 & 1,379 & 1,272 & \\
\hline & \multicolumn{8}{|c|}{ Error Percentage } \\
\hline \multirow[t]{4}{*}{1} & 4 & 3.51 & 4.30 & 3.91 & 11.60 & 12.05 & 11.83 & 7.87 \\
\hline & 5 & 3.18 & 2.60 & 2.89 & 13.39 & 10.21 & 11.80 & 7.35 \\
\hline & 6 & 2.34 & 2.79 & 2.57 & 11.21 & 11.05 & 11.13 & 6.85 \\
\hline & 7 & 2.39 & 2.73 & 2.56 & 11.43 & 9.82 & 10.63 & 6.59 \\
\hline$M$ & & 2.86 & 3.11 & 2.98 & 11.91 & 10.78 & 11.35 & 7.16 \\
\hline \multirow[t]{4}{*}{2} & 4 & 2.34 & 3.20 & 2.77 & 11.44 & 11.14 & 11.29 & 7.03 \\
\hline & 5 & 3.51 & 2.79 & 3.15 & 8.52 & 11.77 & 10.15 & 6.65 \\
\hline & 6 & 1.56 & 4.80 & 3.18 & 10.88 & 10.60 & 10.74 & 6.96 \\
\hline & 7 & 1.95 & 5.86 & 3.91 & 10.77 & 9.93 & 10.35 & 7.13 \\
\hline$M$ & & 2.34 & 4.16 & 3.25 & 10.40 & 10.86 & 10.63 & 6.94 \\
\hline \multirow[t]{4}{*}{3} & 4 & 5.58 & 6.17 & 5.88 & 11.77 & 11.36 & 11.57 & 8.72 \\
\hline & 5 & 0.78 & 4.30 & 2.54 & 11.77 & 12.61 & 12.19 & 7.37 \\
\hline & 6 & 3.51 & 4.91 & 4.21 & 11.72 & 11.44 & 11.58 & 7.90 \\
\hline & 7 & 2.00 & 2.85 & 2.43 & 11.04 & 14.51 & 12.78 & 7.60 \\
\hline$M$ & & 2.97 & 4.56 & 3.76 & 11.58 & 12.48 & 12.03 & 7.90 \\
\hline \multirow[t]{4}{*}{4} & 4 & 3.57 & 5.43 & 4.50 & 9.37 & 6.02 & 7.70 & 6.10 \\
\hline & 5 & 3.51 & 3.91 & 3.71 & 11.44 & 10.40 & 10.92 & 7.32 \\
\hline & 6 & 4.69 & 3.62 & 4.16 & 9.43 & 7.48 & 8.46 & 6.31 \\
\hline & 7 & 2.73 & 2.40 & 2.57 & 12.11 & 11.61 & 11.86 & 7.21 \\
\hline$M$ & & 3.63 & 3.84 & 3.73 & 10.59 & 8.88 & 9.73 & 6.73 \\
\hline $\bar{M}$ & & 2.95 & 3.92 & 3.43 & 11.12 & 10.75 & 10.93 & \\
\hline
\end{tabular}

\section{Further Comments}

The interaction between position and orientation was significant for error proportion $[F(3,93)=4.18$, $\left.M S_{\mathrm{e}}=0.02503, p<.01\right]$ but not for latency $\left[F(3,93)=1.16, M S_{\mathrm{e}}=61,004, p>.30\right]$. 